\title{
Transaction
}

\section{Reactive Electrospinning of Stereoblock Polylactides Prepared via Spontaneous Diels-Alder Coupling of Bis Maleimide-terminated Poly-L-lactide and Bis Furan-terminated Poly-D-lactide}

\author{
Kazunari Masutani ${ }^{* 1}$, Chan Woo Lee ${ }^{* 2}$, Ryosuke Kanki ${ }^{* 1}$,Hideki Yamane ${ }^{* 1}$, and \\ Yoshiharu Kimura ${ }^{* 1}$ \\ ${ }^{* 1}$ Graduate School of Science and Technology, Kyoto Institute of Technology, \\ Matsugasaki, Sakyo-ku, Kyoto 606-8585, Japan \\ ${ }^{* 2}$ Department of Innovative Industrial and Technology, Hoseo University, \\ Baebang-myun, Asan, Chungnam 336-795, Korea
}

\begin{abstract}
Bis maleimide-terminated poly-L-lactide (M-PLLA-M) and bis furan-terminated poly-D-lactide (F-PDLA-F) were synthesized by isocyanate coupling reactions of mono maleimide-terminated PLLA (M-PLLA) and mono furanterminated PDLA (F-PDLA) that had been prepared by the ordinary ring opening polymerization of L- and D-lactides with N-(2-hydroxyethyl)-maleimide and furfurylamine as the initiators, respectively. Both the M-PLLA-M and FPDLA-F were dissolved in $\mathrm{CH}_{2} \mathrm{Cl}_{2}$ in $1: 1$ ratio and subjected to the ordinary electrospinning where the initial polymer concentration was increased up to $20 \mathrm{wt} \%$ because of the prepolymer state of the solute and the fiber diameter could be retained in nanometer to submicron size. The molecular weight of the polymers was found to have increased from $1.0 \times$ $10^{4}$ to 2.5 and $4.5 \times 10^{4}$ after the electrospinning and post annealing, respectively, due to the spontaneous chain extension taking place by the terminal Diels-Alder reaction of M-PLLA-M and F-PDLA-F to form a stereoblock polylactide. The as-spun fibers were amorphous or partially semi-crystalline, whereas the annealed fibers become fully crystalline due to the formation of the stereocomplex showing a melting temperature above $200{ }^{\circ} \mathrm{C}$.
\end{abstract}

(Received 5 December, 2011 ; Accepted 12 December, 2011)

\section{Introduction}

Polylactides (PLA) synthesized from renewable biomass resources are developed as bio-based polymers or ecofriendly materials [1-4]. Two enantiomers exist in PLAs, i.e., poly-L-lactide (PLLA) and poly-D-lactide (PDLA), and the former consisting of naturally abundant L-lactic acid has been utilized as a plastic material. Its application, however, has been limited until now because of its poorer properties compared with the conventional oil-based polymeric materials [5]. Mixing of PLLA and PDLA gives rise to the formation of stereocomplex (sc) crystals whose melting temperature $\left(\mathrm{T}_{\mathrm{m}}\right)$ is $230{ }^{\circ} \mathrm{C}[6-8]$, being $50{ }^{\circ} \mathrm{C}$ higher than that of PLLA. Therefore, this stereocomplex-type polylactide (sc-PLA) is expected to become a heat-resistant bio-based polymer. For manufacturing this sc-PLA, the sc formation must precisely be controlled because the melt-blending of PLLA and PDLA having high molecular weight likely occur simultaneous crystallization of both the homochiral (hc) and sc crystals to retard the properties of the processed materials [6-11]. Various trials have been made thus far for controlling the sc formation effectively. Yamane et al., for example, reported crystallizationinduced mixing of PLLA and PDLA around $190{ }^{\circ} \mathrm{C}$ where the hc crystals are allowed to melt down to form the sc crystals [12]. They also reported that the electrospinning of a solution mixture of PLLA and PDLA can give thin fibers in which preferential sc crystallization is induced. However, the long processing time in the crystallization-induced mixing and the low polymer concentration used in the electrospinning may retard the processabilities. Recently, we demonstrated that stereoblock-type PLAs (sb-PLA) consisting of PLLA and PDLA sequences can easily form the sc crystals with little hc crystallization [13-21], because they ought to have a mixing state of the enantiomeric PLLA and PDLA blocks in molecular level. Furthermore, we showed that the sbPLAs can efficiently be formed by spontaneous DielsAlder coupling of PLLA and PDLA prepolymers having dienophile (maleimide) and diene (anthracene) terminals, respectively [21]. The related chain-extension based on Diels-Alder reaction had ever been reported by Yoshie et al., who used maleimide linkers for chain coupling of bis 
furan-terminated polyesters [22,23]. Inoue et al. also exhibited the Diels-Alder coupling of bis furanterminated PLLA with maleimide linkers [24,25]. These examples indicate that the terminal Diels-Alder reaction between furan- and maleimide-terminated prepolymers can be a good method for coupling polymer chains having different structure and properties. In the present study, we apply this terminal coupling method to the synthesis of stereo multi-block PLAs (m-sb-PLA) as well as to the reactive electrospinning of sb-PLA fibers in which the concentration of the dope of the prepolymers can efficiently be increased for better spinnability and the polymer molecular weight can be enhanced during the spinning and post-annealing of the fibers. For this purpose, we synthesize bis maleimide-terminated PLLA and bis furan-terminated PDLA as the telechelic prepolymers from which m-sb-PLAs can be formed spontaneously (Fig. 1-3). This synthetic method is characterized by the dual terminal couplings : at first, mono-furfuryl PDLA (F-PDLA) and mono-maleimid-Nyl PLLA (M-PLLA) prepolymers are prepared by the ordinary ring-opening polymerization (ROP) of L- and Dlactides, respectively, by using initiators containing the corresponding functional groups. Both of these prepolymers are then allowed to dimerize by the first terminal coupling reaction with 1,6-hexamethylene diisocyanate (HMDI) to synthesize bis-maleimid-N-yl PDLA (M-PDLA-M) and bis-furfuryl PDLA (F-PDLA-F) (Fig. 1 and 2). Note that the terminal moieties involving maleimide and furan groups are abbreviated as $\mathrm{M}$ and $\mathrm{F}$, respectively. Both the di-functional (telechelic) polymers are then mixed in solution and subjected to the electrospinning during which the second coupling reaction (the terminal Diels-Alder reaction) is induced to finally obtain m-sb-PLAs in fiber form (Fig. 3). Annealing of the fibers can also provide further increase in molecular weight of m-sb-PLA. Here, we demonstrate the whole reaction processes of this new approach along with the analysis of morphology of the electrospun fibers and the molecular weight change of the m-sb-PLA.

\section{Experimental}

\subsection{Materials}

L- and D-Lactides were supplied by Musashino Chemical Laboratory, Ltd. (Tokyo). Their optical purity was over 99.9 \%ee. Furfurylamine (FA, 98\%) and HMDI were supplied by Tokyo Chemical Industry Co., Ltd. (Tokyo). FA was distilled twice in high vacuum before use. N-(2-Hydroxyethyl)maleimide (MA, 99\%) and tin 2octoate $\left(\mathrm{Sn}(\mathrm{Oct})_{2}, 95 \%\right)$ were purchased from Strem Chemicals (Newburyport, MA) and Sigma-Aldrich (St. Louis, MO), respectively, via Sasaki Chemical Co., Ltd. (Kyoto). $\mathrm{Sn}(\mathrm{Oct})_{2}$ was distilled in high vacuum and dissolved in toluene in a concentration of $0.2 \mathrm{~g} / \mathrm{ml}$. Dichloromethane $\left(\mathrm{CH}_{2} \mathrm{Cl}_{2}, \quad 99.5 \%\right)$ and 1,1,1,3,3,3hexafluoro-2-propanol (HFIP, 98\%) were purchased from Kanto Chemical Co., Ltd. (Tokyo) and Central Glass Co., Ltd. (Hofu, Yamaguchi, Japan), respectively. These reagents and solvents were used without purification unless specifically noted.

\subsubsection{Synthesis of F-PDLA-F via F-PDLA}

Both D-lactide (10.0 g, $69.4 \mathrm{mmol})$ and FA (194 mg, $2.00 \mathrm{mmol}$ ) were charged into a $50 \mathrm{~mL}$ two-necked flask

$$
\underset{180{ }^{\circ} \mathrm{C}, 15 \mathrm{~min}}{\mathrm{HMDI}}
$$

Fig. 1 Synthesis of F-PDLA-F by the First Isocyanate Coupling of F-PDLA.

$$
\text { 180 }{ }^{\circ} \mathrm{C}, 15 \mathrm{~min}
$$

Fig. 2 Synthesis of M-PLLA-M by the First Isocyanate Coupling of M-PLLA.

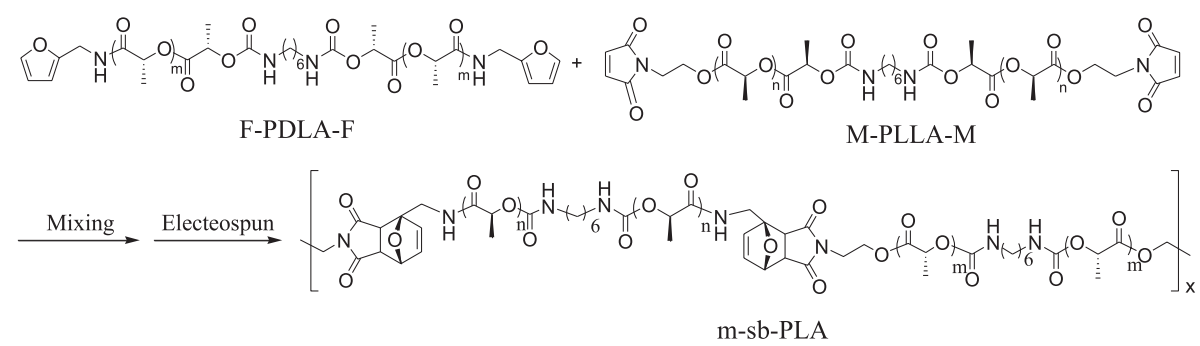

Fig. 3 Synthesis of m-sb-PLA by the Second Diels-Alder Coupling of F-PDLA-F and M-PLLA-M. 
equipped with a mechanical stirrer. The flask was evacuated at $10 \mathrm{~Pa}$ and room temperature for $1 \mathrm{~h}$ and purged with nitrogen. This evacuation/nitrogen purge was repeated 6 times for thoroughly drying the reactants.

Subsequently, a portion of the catalyst solution (including $0.027 \mathrm{mmol}$ of $\mathrm{Sn}(\mathrm{Oct})_{2}$, i.e., $0.04 \mathrm{~mol} \%$ of $\mathrm{D}$ lactide) was added to the monomer mixture with a syringe. The flask was desiccated at high vacuum for $1 \mathrm{~h}$ to remove the toluene at room temperature and was filled with nitrogen. It was then heated at $180{ }^{\circ} \mathrm{C}$ for $25 \mathrm{~min}$ with stirring for polymerization. In the final step of this polymerization, exactly half equivalent molar amount of HMDI (169 mg, $1.00 \mathrm{mmol}$ ) relative to the FA was added to the system and reacted with the polymerization product for 15 min under stirring with the other conditions being identical. The reaction product finally obtained was dissolved in a $\mathrm{CH}_{2} \mathrm{Cl}_{2}$ and re-precipitated into an excess of methanol. The precipitates were filtered, washed with methanol several times, and dried in vacuum at $80{ }^{\circ} \mathrm{C}$ for $6 \mathrm{~h}$. The initial ROP product and its coupling product are named F-PDLA(5) and F-PDLA-F(10), respectively, by putting their $M_{n}$ numbers in $\times 10^{3}$ in the parentheses. The $M_{n}$ value of the coupling product should be almost twice that of the ROP product.

F-PDLA(5): ${ }^{1} \mathrm{H}$ NMR $\left(600 \mathrm{MHz}\right.$, in $\mathrm{CDCl}_{3}$, Fig. 4a) : $\delta: 1.56-1.6$ (d, $\mathrm{CH}_{3}$ of the lactate unit), 4.3-4.4 (q, $\mathrm{CH}-\mathrm{OH}$ of the terminal lactate), 5.1-5.2 (q, $\mathrm{CH}$ of the lactate unit), and 4.4-4.5 (d, N-CH2-C of the FA unit), 6.22 (d, $\mathrm{C}=\mathrm{CH}-\mathrm{C}$ of the FA unit), 6.31 (dd, $\mathrm{C}-\mathrm{CH}=\mathrm{C}$ of the FA unit), 6.51 (t, -C-NH-C- of the FA unit) and 7.35 (d, -C-CH-O- of the FA unit). The $\mathrm{M}_{n}$ (nmr) was determined by the integral ratios of the signals at $\delta: 5.1$ 5.2 and $\delta: 4.3-4.4 \mathrm{ppm}$.

F-PDLA-F(10) : ${ }^{1} \mathrm{H}$ NMR (600 MHz, in $\mathrm{CDCl}_{3}$, Fig. 4b) : $\delta: 1.3-1.4$ (m, C-CH$-\mathrm{C}$ of the HMDI unit), 1.561.6 (d, $\mathrm{CH}_{3}$ of the lactate unit), 3.1-3.2 (q, N-CH$-\mathrm{C}$ of the HMDI unit), 4.4-4.5 (d, N-CH $\mathrm{H}_{2} \mathrm{C}$ of the FA unit), 4.9-5.0 (q, C-CH-OC(O)NH- of the linking lactate), 5.1-5.2 (q, $\mathrm{CH}$ of the lactate unit), 6.22 (d, $\mathrm{C}=\mathrm{CH}-\mathrm{C}$ of the FA unit), 6.31 (dd, C-CH=C of the FA unit), 6.51 (t, -C-NH-C- of the FA unit), and 7.35 (d, -C-CH-O- of the FA unit)

\subsubsection{Synthesis of M-PLLA-M via M-PLLA}

Both L-lactide (10.0 g, $69.4 \mathrm{mmol})$ and MA (290.0 mg, $2.05 \mathrm{mmol}$ ) were charged into a $50 \mathrm{~mL}$ twonecked flask equipped with a mechanical stirrer. Then, the following polymerization as well as the coupling reaction with HMDI was carried out as described above. The initial ROP product and its coupling product are named M-PLLA(5) and M-PLLA-M(10), respectively, as described above.
M-PLLA(5) : ${ }^{1} \mathrm{H}$ NMR (600 MHz, in $\mathrm{CDCl}_{3}$, Fig. 5a) : $\delta: 1.56-1.6\left(\mathrm{~d}, \mathrm{CH}_{3}\right.$ of the lactate unit), 4.3-4.4 (q, $\mathrm{CH}-\mathrm{OH}$ of the terminal lactate), 5.1-5.2 (q, $\mathrm{CH}$ of the lactate unit), and 3.7-3.9 (m, N-CH $\mathrm{CH}_{2} \mathrm{C}$ of the MA unit), 4.2-4.4 (m, C- $\mathrm{CH}_{2}-\mathrm{O}$ of the MA unit), and 6.75 (s, $-\mathrm{CH}=$ $\mathrm{CH}$ - of the MA unit). The $\mathrm{M}_{\mathrm{n}}(\mathrm{nmr})$ was determined by the integral ratios of the signals at $\delta: 5.1-5.2$ and $\delta: 4.3-$ $4.4 \mathrm{ppm}$. Since the latter signal duplicated with the $\mathrm{C}-\mathrm{CH}_{2}-\mathrm{O}$ signal of the MA unit, its integral ratio was evaluated in reference to that of the $\mathrm{N}-\mathrm{CH}_{2}-\mathrm{C}$ signal of the MA units.

M-PLLA-M(10) : ${ }^{1} \mathrm{H}$ NMR $\left(600 \mathrm{MHz}\right.$, in $\mathrm{CDCl}_{3}$, Fig. 5b) : $\delta: 1.3-1.4$ (m, C-CH$-\mathrm{C}$ of the HMDI unit), 1.56-1.6 (d, $\mathrm{CH}_{3}$ of the lactate unit), 3.1-3.2 (q, N-CH$-\mathrm{C}$ of the HMDI unit), 3.7-3.9 (m, N-CH2-C of the MA unit), 4.2-4.4 (m, C-CH$-\mathrm{O}$ of the MA unit), 4.9-5.0 (q, C-CH$\mathrm{OC}(\mathrm{O}) \mathrm{NH}-$ of the linking lactate), 5.1-5.2 (q, $\mathrm{CH}$ of the lactate unit), and 6.75 (s, $-\mathrm{CH}=\mathrm{CH}$ - of the MA unit).

\subsubsection{Diels-Alder coupling of F-PDLA-F and M-PLLA-M}

Stoichiometric amounts of F-PDLA-F $(6.0 \mathrm{~g})$ and M-PLLA-M (6.0 g) were charged into a glass ample with stirrer tip and dissolved in a mixed solvent $(20 \mathrm{ml})$ of $\mathrm{CH}_{2} \mathrm{Cl}_{2}$ and HFIP $\left(\mathrm{CH}_{2} \mathrm{Cl}_{2} / \mathrm{HFIP}=4 / 1 \mathrm{v} / \mathrm{v} \%\right)$. The resultant solution was stirred at room temperature for $24 \mathrm{~h}$ and poured into an excess of methanol for re-precipitation of the product m-sb-PLA. The precipitates were filtered, washed with methanol several times, and dried in vacuum at $80{ }^{\circ} \mathrm{C}$ for $6 \mathrm{~h}$.

m-sb-PLA : ${ }^{1} \mathrm{H}$ NMR (600 MHz, in $\mathrm{CDCl}_{3}$, Fig. 6) : $\delta: 1.3-1.4$ (m, C-CH$H_{2}-\mathrm{C}$ of the HMDI unit), 1.56-1.6 (d, $\mathrm{CH}_{3}$ of the lactate unit), 2.8-3.15 (d, -C-CH-CO of exo type of the linking between FA and MA unit), 3.1-3.2 (q, $\mathrm{N}-\mathrm{CH}_{2}-\mathrm{C}$ of the HMDI unit), 3.22-3.7 (d, -C-CH-CO of endo type of the linking between FA and MA unit), 3.73.9 (m, N-CH$H_{2}-\mathrm{C}$ of the MA unit), 3.9-4.2 (s, C-CH $H_{2}-\mathrm{N}$ of endo/exo type of the linking FA unit), 4.2-4.4 (m, C-CH $\mathrm{CH}_{2-}$ $\mathrm{O}$ of the MA unit), 4.4-4.5 (d, N-CH$-\mathrm{C}$ of the FA unit), 4.9-5.0 (q, C-CH-OC(O)NH- of the linking lactate), 5.15.2 (q, $\mathrm{CH}$ of the lactate unit), 5.2-5.3 ( $\mathrm{t}, \mathrm{C}-\mathrm{CH}-\mathrm{O}$ of the linking between FA and MA unit), 6.51 ( $\mathrm{t},-\mathrm{C}-\mathrm{N} H$-C- of the FA unit), 6.28-6.7 (d, $\mathrm{C}=\mathrm{CH}-\mathrm{C}$ of the FA unit), and $6.22(\mathrm{~d}, \mathrm{C}=\mathrm{C} H-\mathrm{C}$ of the unreacted FA unit), 6.31 (dd, $\mathrm{C}-\mathrm{C} H=\mathrm{C}$ of the unreacted FA unit), 6.75 (s, $-\mathrm{CH}=\mathrm{CH}$ of the unreacted MA unit), and 7.35 (d, $-\mathrm{C}-\mathrm{CH}-\mathrm{O}-$ of the unreacted FA unit).

\subsection{Electrospinning}

A typical example was as follows. Both F-PDLA- F (10) (1.0 g) and M-PLLA-M(10) (1.0 g) were dissolved in a predetermine amount of a mixed solvent of $\mathrm{CH}_{2} \mathrm{Cl}_{2}$ and 
HFIP $\left(\mathrm{CH}_{2} \mathrm{Cl}_{2} / \mathrm{HFIP}=4 / 1 \mathrm{v} / \mathrm{v} \%\right)$ by stirring at room temperature for $1 \mathrm{~h}$. The resultant solution (dope) having a polymer concentration of $5,10,15$, or $20 \mathrm{wt} \%$ was charged into a syringe $(1 \mathrm{ml}$ size $)$ with a thin needle $(27$ $\mathrm{G}$ : inner diameter (ID) $=0.21 \mathrm{~mm}$, outer diameter (OD) $=0.42 \mathrm{~mm}$, and length $=38 \mathrm{~mm})$. The syringe was then installed on a micro feeder pump (Furue Science, Tokyo) to extrude the dope from the needle at a constant rate of $2 \mu \mathrm{Lmin}^{-1}$. The extrudate was electro-sprayed by using an electrospinning setup reported before [26]. The collector consisted of aluminum sheet fixed on a drum $(7 \mathrm{~cm}$ in diameter) rotating at a constant speed of $400 \mathrm{rpm}(2.9 \mathrm{~m} / \mathrm{s}$ in line speed) and grounded with a wire placed in the center of the drum. The nozzle-to-drum surface distance was set at $10 \mathrm{~cm}$, and a high voltage $(5,10,15$, or $20 \mathrm{kV})$ was applied between the syringe needle and the collector. The obtained fibers were annealed at $140{ }^{\circ} \mathrm{C}$ for $1.5 \mathrm{~h}$.

\subsection{Measurements}

Number- $\left(\mathrm{M}_{\mathrm{n}}(\mathrm{gpc})\right)$ and weight-average $\left(\mathrm{M}_{\mathrm{w}}(\mathrm{gpc})\right)$ molecular weights were determined by gel permeation chromatography (GPC) that was recorded on a system comprising Shimadzu (Kyoto) LC-20AD HPLC pump and a Shimadzu RID-10A differential refractive index detector. Two Tosoh (Tokyo) TSK gel Super HZM-N columns (bead-size : $3.0 \mu \mathrm{m}$, molecular weight exclusion range : 700,000-500 Da) with a Tosoh TSK Super HZ-L guard column $(4.6 \mathrm{mmID} \times 3.5 \mathrm{~cm})$ were installed on the system, and chloroform was used as the eluent. The measurement was done at $30{ }^{\circ} \mathrm{C}$ and at $0.25 \mathrm{mLmin}^{-1}$ in flow rate. Polystyrene standards were used for calibrating the molecular weights ranging from 1,090,000 to $500 \mathrm{Da}$. ${ }^{1} \mathrm{H}$ NMR spectra were recorded at $600 \mathrm{MHz}$ on a Bruker (Karlsruhe, Germany) AV600 spectrometer. Deuterated chloroform, involving 0.03 vol- $\%$ tetramethylsilane (TMS) as the internal standard, was used as the solvent. Differential scanning calorimetry (DSC) was conducted on a BrukerAXS DSC3100SA thermal analyzer under a nitrogen gas at a heating rate of $10{ }^{\circ} \mathrm{Cmin}^{-1}$. A sample of about $2.0 \mathrm{mg}$ was heated up to $230^{\circ} \mathrm{C}$ in the first scan, quenched in liquid nitrogen, and heated again from $30^{\circ} \mathrm{C}$ to $240{ }^{\circ} \mathrm{C}$ in the second heating scan. Wide-angle X-ray scattering (WAXS) was recorded on a Rigaku (Tokyo) RINT-2500 X-ray system using nickel-filtered $\mathrm{Cu}-\mathrm{K} \alpha$ radiation $(\lambda=0.1542 \mathrm{~nm})$ at $40 \mathrm{kV}$ and $50 \mathrm{~mA}$. The scattered $\mathrm{X}$-ray was recorded in a $2 \theta$ angle range of 5-40 at a scan rate of $4^{\circ} \mathrm{min}^{-1}$. Scanning electron microscopy (SEM) was performed on an electron microscope (KEYENCE Corp. VE-7800) operated at $10 \mathrm{kV}$. The sample was gold-coated on an aluminum stage prior to observation. The average diameter of the electronspun fibers was estimated as follows. A SEM photo of the sample fibers lying on the stage was magnified up to 100 10,000 times, and approximately 40 fibril images were randomly selected. The diameters of these fibrils were measured and averaged to determine the average diameter of the fibers.

\section{Results and discussion}

\subsection{Synthesis of F-PDLA-F and M-PLLA-M}

As shown in Fig. 1 and 2, the mono-furan terminated F-PDLA(5) and mono-maleimide terminated M-PLLA(5) were first prepared by ROP of D- and L-lactides using FA and MA as the initiators, respectively. The obtained prepolymers having a mono-hydroxyl terminal were directly reacted with HMDI in one pot (without isolation) for their dimerization. The urethane formation of the hydroxyl terminals was well catalyzed by $\mathrm{Sn}(\mathrm{Oct})_{2}$ that had been used in the ROP of lactides, and the dimeric products F-PDLA-F and M-PLLA-M were yielded in high conversion in such a short reaction time as $15 \mathrm{~min}$ (Table 1). Fig. 4 and 5 show the ${ }^{1} \mathrm{H}$ NMR spectra of FPDLA-F(10) and M-PLLA-M(10) as compared with those of their prepolymers F-PDLA(5) and M-PLLA(5), respectively. The signal assignments are as shown by the alphabetical symbols and summarized in Experimental Section. In short, F-PDLA(5) (Fig. 4a) and M-PLLA(5) (Fig. 5a) exhibit a hydroxymethine signal due to the terminal lactate units at $\delta: 4.3-4.4 \mathrm{ppm}$ (signal $H$ in the spectrum of F-PDLA and signal $F$ duplicating with the $\mathrm{O}-\mathrm{CH}_{2}$ - signal $\mathrm{C}$ of the MA moiety in the spectrum of M-PLLA). These hydroxymethine signals $H$ and $F$ are completely absent in the F-PDLA-F (Fig. 4b) and M-PLLA-M (Fig. 5b), respectively, and replaced by the carbamoyloxymethine signals shown at $\delta: 4.9-5.0 \mathrm{ppm}$ (signal $h$ in spectrum $4 \mathrm{~b}$ and signal $f$ in spectrum $5 \mathrm{~b}$ ) that are attributable to the lactate units linking with the urethane groups. In addition, both F-PDLA-F(10) and M-PLLA-M(10) exhibit the HMDI-originated alkylenemethylene signals at $\delta: 1.3-1.4 \mathrm{ppm}$ (signal $k$ in spectrum $4 \mathrm{~b}$ and signal $i$ in spectrum 5b) and $\mathrm{N}$-methylene signals at $\delta: 3.1-3.2 \mathrm{ppm}$ (signal $j$ in spectrum $4 \mathrm{~b}$ and signal $h$ in spectrum $5 \mathrm{~b}$ ), whereas the $\mathrm{N}$-methylene signal of HMDI is shown at $\delta: 3.5-3.6 \mathrm{ppm}$ as a very weak signal. This signal was confirmed to almost disappear after purification. The conversion of the coupling reaction can be determined from the integral ratios of these $\mathrm{N}$-methylene signals (Table 1). On the other hand, the signals from the furan and maleimide moieties are kept unchanged before and after the coupling. 
These analyses strongly support the dimeric structures of M-PLLA-M(10) and F-PDLA-F(10) in which M-PLLA (5) and F-PDLA(5) are connected by urethane linkages, respectively. The $M_{n}(n m r)$ of the coupling products was determined by the integral ratios of the methine signals of the linking units $\mathrm{C}-\mathrm{CH}-\mathrm{OC}(\mathrm{O}) \mathrm{NH}-(\delta: 4.9-5.0 \mathrm{ppm})$ and the main chain units $\mathrm{C}-\mathrm{CH}-\mathrm{OC}(\mathrm{O})(\delta: 5.1-5.2 \mathrm{ppm})$ considering their dimeric block structure. The resultant $M_{n}(n m r)$ values are almost correspondent to the $M_{n}($ th $)$ values (Table 1). Fig. 6 shows typical GPC curves of F-PDLA-F(10) and M-PLLA-M(10) as compared with those of F-PDLA(5) and M-PLLA(5). It is revealed that the curves of the former products shift to higher molecular weight regions without any shoulder peak and that the $\mathrm{M}_{\mathrm{n}}(\mathrm{gpc})$ values of F-PDLA-F and M-PLLA-M are almost twice those of F-PDLA(5) and M-PLLA(5), respectively (Table 1 ). These results also strongly support the dimeric structures of F-PDLA-F(10) and M-PLLA-M (10) and that their $M_{n}$ (th) values are assumed to be approximately $1.0 \times 10^{4}$, i.e., twice those of the F-PDLA (5) or M-PLLA(5).

\subsection{Diels-Alder coupling of F-PDLA-F(10) and M-PDLA-M(10)}

Both F-PDLA-F(10) and M-PDLA-M(10) were dissolved in $\mathrm{CH}_{2} \mathrm{Cl}_{2}$ in a concentration of $30 \mathrm{wt} \%$ and stirred at room temperature for 1 day. Fig. 7 shows the ${ }^{1} \mathrm{H}$ NMR spectrum of the resultant adduct. Its comparison with the spectra of F-PDLA-F(10) (Fig. 4b) and M-PDLA-M(10) (Fig. 5b) reveals that in addition to the signals due to the $\mathrm{F}$ and $\mathrm{M}$ moieties of the original prepolymers new signals have appeared around $\delta: 6.5$, 3.5 , and $3.0 \mathrm{ppm}$. These signals are reasonably assigned to the bicyclic moieties of the Diels-Alder adducts of $F$ and $M$ terminals (see Experimental section). Therefore, the occurrence of terminal coupling of F-PDLA-F(10) and M-PDLA-M(10) is supported. The conversion of the Diels-Alder reaction is estimated to be approximately

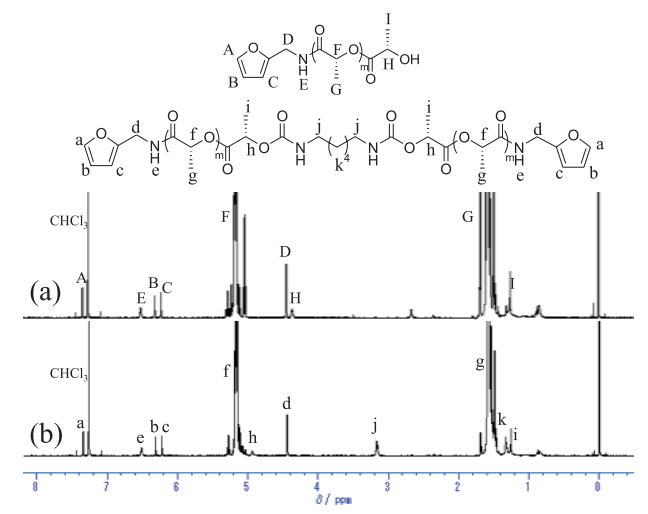

Fig. $4{ }^{1} \mathrm{H}$ NMR spectra of (a) F-PDLA(5) and (b) F-PDLA-F(10).
$63 \%$ at this condition. Both the endo and exo products are involved in a ratio of endo/exo $=36.2 / 26.8$. Since the adduct isolated after 3 days of stirring in solution showed the identical ${ }^{1} \mathrm{H}$ NMR spectrum, the Diels-Alder reaction was not thought to proceed further under the present condition. The typical GPC curve of the adduct is involved in Fig. 6 (e). The increased molecular weight is clearly indicated although the molecular weight distribution becomes significantly wider.

\subsection{Electro-spinning of a mixture of M-PLLA-M (10) and F-PDLA-F(10)}

Several solutions (dopes) having different concentrations $(5-20 \mathrm{wt} \%)$ of a $1: 1$ prepolymer mixture of M-PLLA-M(10) and F-PDLA-F(10) in $\mathrm{CH}_{2} \mathrm{Cl}_{2}$ were subjected to the electrospinning by using a rotating drum target. Fig. 8 shows the SEM images of the deposited fibers obtained by applying a constant voltage of $15 \mathrm{kV}$ between the needle and the grounded target. It is revealed that the fibers possess so-called bead-on-string and entangled fibril morphologies at low (5 and $10 \mathrm{wt} \%$ ) and high (15 and $20 \mathrm{wt} \%$ ) concentrations, respectively. Since the $\mathrm{M}_{\mathrm{n}}$ of the prepolymers is so low, the viscosity of the dilute dopes is not sufficiently high to yield continuous fibril spray. With increasing the concentration above $15 \mathrm{wt} \%$, the chain entanglement is better to make the preferential fibril formation possible, although the fast evaporation of the solvent sometimes clogged the needle.

In our former study [27], we found out that the single use of $\mathrm{CH}_{2} \mathrm{Cl}_{2}$ as the solvent likely brings the beading in the spray of PLLA. Since the solute polymer used in this previous study had an $\mathrm{M}_{\mathrm{n}}$ as high as $1.0 \times 10^{5}$, the polymer concentration was limited to $7-8 \mathrm{wt} \%$ for retaining the fluidity of the dope, causing the beading. Here, the polymer concentration of the dope can be increased to such a high level as to make the filament formation continuous because the solute polymer is in prepolymer state. To make the solvent evaporation much

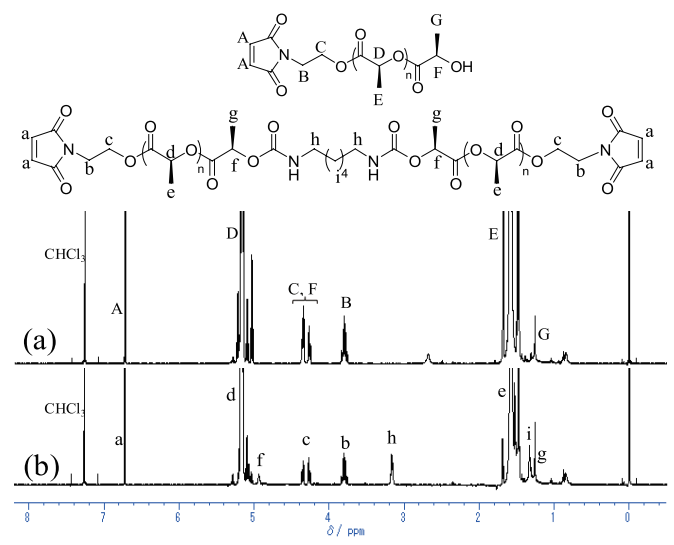

Fig. $5{ }^{1} \mathrm{H}$ NMR spectra of (a) M-PLLA (5) and (b) M-PLLA-M (10). 


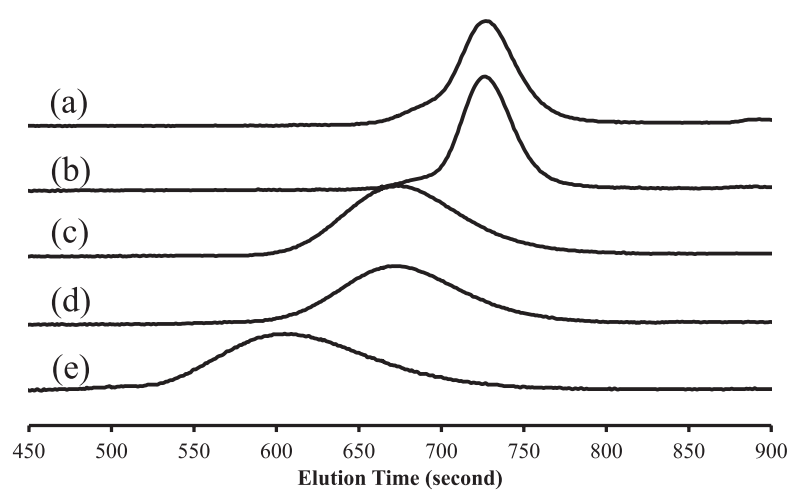

Fig. 6 GPC curves of (a) F-PDLA(5), (b) M-PLLA(5), (c) F-PDLA-F(10), (d) M-PLLA-M (10), and (e) the m-sb-PLA (chain-extended product).
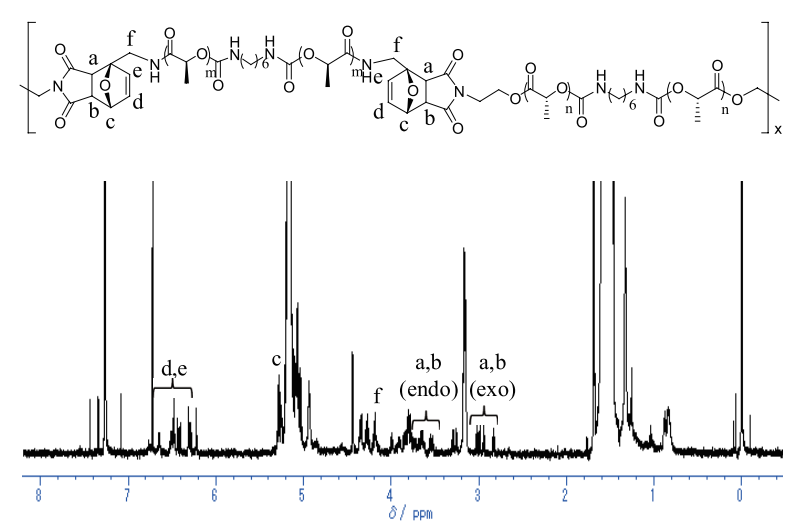

Fig. 7 A typical ${ }^{1} \mathrm{H}$ NMR spectrum of the Diels-Alder adduct of F-PDLA-F and M-PLLA-M obtained in $\mathrm{CH}_{2} \mathrm{Cl}_{2}$ at $30 \mathrm{wt} \%$ after 1day.

Table 1 Typical results of synthesis of F-PDLA-F and M-PLLA-M and their Diels-Alder coupling to form m-sb-PLA.

\begin{tabular}{|c|c|c|c|c|c|c|c|c|c|}
\hline \multirow[t]{2}{*}{ Sample } & \multirow[t]{2}{*}[\mathrm{M}]{$_{0} /[]_{0}$} & \multirow[t]{2}{*}{$\begin{array}{c}{[\mathrm{HMDI}]_{0}} \\
/[]_{0}^{\mathrm{a}}\end{array}$} & \multirow{2}{*}{$\begin{array}{c}\text { ROP } \\
\text { conv. }\end{array}$} & \multirow{2}{*}{$\begin{array}{l}\text { HMDI } \\
\text { conv. } \\
(\%) \\
\end{array}$} & \multirow{2}{*}{$\begin{array}{c}\mathrm{Mn}(\mathrm{th}) \\
\times 10^{3} \\
\end{array}$} & \multirow{2}{*}{$\begin{array}{c}\mathrm{Mn}(\mathrm{nmr}) \\
\times 10^{3}\end{array}$} & \multirow{2}{*}{$\frac{\operatorname{Mn}(g p c)^{b}}{\times 10^{3}}$} & \multirow{2}{*}{$\frac{\operatorname{Mw}(g p c)^{b}}{\times 10^{3}}$} & \multirow[t]{2}{*}{$\mathrm{Mw} / \mathrm{Mn}^{\mathrm{b}}$} \\
\hline & & & & & & & & & \\
\hline F-PDLA(5) & 34.7 & & 95.3 & & 5.0 & 4.7 & 8.3 & 10.8 & 1.3 \\
\hline F-PDLA-F(10) & & 0.5 & & 98.6 & 10 & 9.4 & 15.5 & 25.5 & 1.5 \\
\hline M-PLLA(5) & 33.9 & & 95.5 & & 4.9 & 4.8 & 9.1 & 11.8 & 1.3 \\
\hline M-PLLA-M(10) & & 0.5 & & 97.4 & 9.8 & 9.6 & 16.3 & 25.3 & 1.6 \\
\hline m-sb-PLA & & & & & & & 37.5 & 105 & 2.8 \\
\hline
\end{tabular}

slower, the solvent may be changed to a mixture of $\mathrm{CH}_{2} \mathrm{Cl}_{2} /$ dimethylformamide (DMF) $(9: 1 \mathrm{wt} / \mathrm{wt})$ as we reported before [28].

Fig. 9 shows the SEM images of the fibers electrospun at different voltages $(5-20 \mathrm{kV})$ at an identical polymer concentration of $20 \mathrm{wt} \%$. In each case, the continuous fibril morphology is shown. The fibrils become thinner with increasing the voltage, and their diameter reaches less than $200 \mathrm{~nm}$ at $20 \mathrm{kV}$, having an apparent uniformity.

Fig. 10 shows typical GPC curves of the fibers electrospun at different voltages. Here, the data are for the nanometer-size fibers obtained with the dope of $10 \mathrm{wt} \%$ in polymer concentration, and by which the characteristic nature was the most clearly exhibited although similar results were also obtained with the fibers electrospun from the dopes having higher polymer concentrations. The curves of the electrospun fibers are known to shift to higher molecular weight regions compared to the curve of the polymer isolated from the dope. Furthermore, in the annealed fiber the shift of the curve is more evident. Table 2 summarizes the $\mathrm{M}_{\mathrm{n}}$ and $\mathrm{M}_{\mathrm{w}}$ data determined from these GPC curves. The $M_{n}$ of the polymer isolated just after the mixing of the both prepolymers became about $1.8 \times 10^{4}$, being only slightly larger than the $M_{n}$ values of the starting prepolymers. This fact suggests that little polymer coupling takes place between M-PLLA-M(10) and F-PDLA-F(10) in the solution state where the rate of Diels-Alder reaction is slow. In the electrospun fibers, the $\mathrm{M}_{\mathrm{n}}$ values became about $2.5 \times 10^{4}$, being almost similar regardless of the applied voltages. This increase in $M_{n}$ is attributed to the partial terminal coupling of the prepolymers during the rapid condensation of the electrospray. When the fibers obtained at $20 \mathrm{kV}$ were annealed at $140{ }^{\circ} \mathrm{C}$ that was higher than the crystallization temperature $\left(\mathrm{T}_{\mathrm{c}}\right)$ of sc-PLA, the $\mathrm{M}_{\mathrm{n}}$ values increased up to $4.5 \times 10^{4}$ that is comparable to the $M_{n}$ range of the PLA materials ordinarily utilized.

Fig. 11 compares the WAXS patterns of the fibers electrospun from a solution having a polymer concentration of $10 \mathrm{wt} \%$. It is shown that the electrospun fibers are mostly amorphous except the fibers electrospun at $5 \mathrm{kV}$ consisting mainly of beads. The scatterings at 12 , 21 , and $24^{\circ}$ from the triclinic sc crystals become stronger and narrower in the annealed fibers, supporting the increased crystallinity. None of scattering from the hc crystals (e.g., at $17^{\circ}$ ) is exhibited. It has previously been reported that the crystallization of the electrospun fibers is retarded because of the rapid solvent evaporation during the electrospinning [29-33]. Particularly, fibers prepared 
from polymers having high $\mathrm{T}_{\mathrm{g}}$ are usually amorphous and ought to be crystallized by the post annealing. The present $\mathrm{m}$-sb-PLA fibers prepared by the chain extension seems to have exhibited similar behavior. Fig. 12 shows the DSC curves of the fibers electrospun at $20 \mathrm{kV}$ in voltage and $20 \mathrm{wt} \%$ in polymer concentration as well as their annealed fibers in the first heating scan. The electrospun at a voltage below $15 \mathrm{kV}$ exhibits a weak crystallization peak below $80^{\circ} \mathrm{C}$ as well as the melting peak of sc crystals around $215^{\circ} \mathrm{C}$. Although the heat of crystallization $\left(\Delta \mathrm{H}_{c}\right)$ seems to be much smaller than the heat of fusion of sc crystals $\left(\Delta \mathrm{H}_{\mathrm{m}}\right)$ in each case, a very broad exothermic behaivior is noted in the region from 90 to $180{ }^{\circ} \mathrm{C}$, indicating gradual crystallization occurring with the increase in temperature. The fibers electrospun at $20 \mathrm{kV}$ only show the latter crystallization process, whereas the annealed fibers show only the sc crystal fusion. Although the above WAXS data indicated the amorphous nature of the as-spun fibers, the DSC data

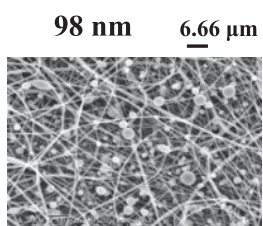

(a)

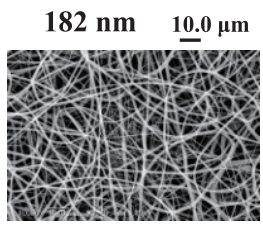

(c)

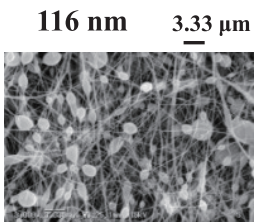

(b)

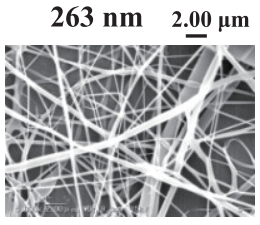

(d)
Fig. 8 SEM images of fibers electrospun at different concentrations of (a) $5 \mathrm{wt} \%$, (b) $10 \mathrm{wt} \%$, (c) $15 \mathrm{wt} \%$, and (d) $20 \mathrm{wt} \%$ by applying a constant voltage of $15 \mathrm{kV}$ between the needle and the grounded target.

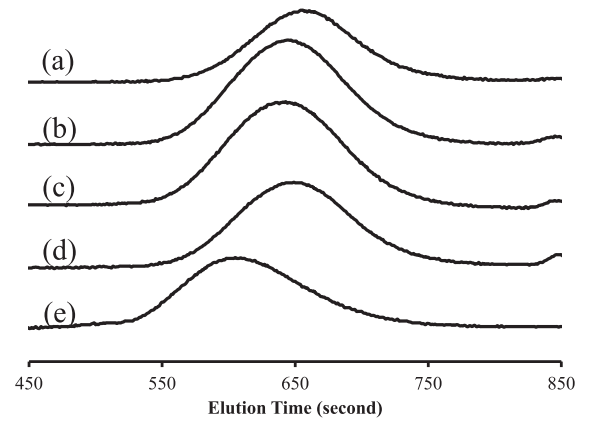

Fig. 10 GPC curves of the electrospun and annealed fibers obtained at different voltages from the dope of $10 \mathrm{wt} \%$ in polymer concentration: (a) as-isolated from solution (control), electrospun at (b) $10 \mathrm{kV}$, (c) $15 \mathrm{kV}$, (d) $20 \mathrm{kV}$, and (e) electrospun at $20 \mathrm{kV}$ and annealed at $140{ }^{\circ} \mathrm{C}$. strongly suggest partial crystallinity for them.

This contradiction may be attributed to the formation of very small sc crystallites having such a size that could not be detected by WAXS. Since no retro Diels-Alder reaction was noted in the DSC curves up to $240{ }^{\circ} \mathrm{C}$, the present adducts ought to be thermally stable up to the $T_{m}$ of sc crystals. Table 3 summarizes the DSC data for the representative three samples. In the $1^{\text {st }}$ heating scan of the fibers electrospun at $20 \mathrm{kV}$, the $\Delta \mathrm{H}_{\mathrm{m}}$ became slightly smaller than that of the control sample (isolated from the prepolymer solution). Even after the annealing the value did not become as large as that of the control. This decrease in $\Delta \mathrm{H}_{\mathrm{m}}$ for the electrospun fibers may be attributed to the limited chain extension in the thin fibrils (61 nm in diameter). In the second heating, each sample showed both the cold crystallization exotherm and the melting endotherm around 85 and $215{ }^{\circ} \mathrm{C}$, respectively, together with the glass transition $\left(\mathrm{T}_{\mathrm{g}}\right)$ around $55{ }^{\circ} \mathrm{C}$. No melting behavior of hc crystals was noted, either. The

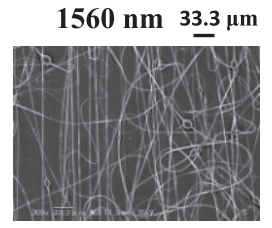

(a)

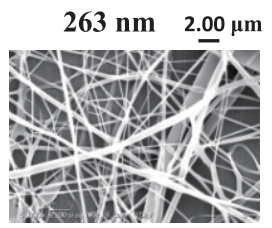

(c)

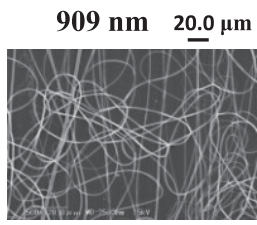

(b)

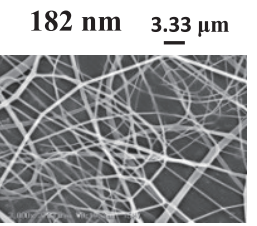

(d)
Fig. 9 SEM images of fibers electrospun at different voltages of (a) $5 \mathrm{kV}$, (b) $10 \mathrm{kV}$, (c) $15 \mathrm{kV}$, and (d) $20 \mathrm{kV}$ at an identical polymer concentration of $20 \mathrm{wt} \%$.

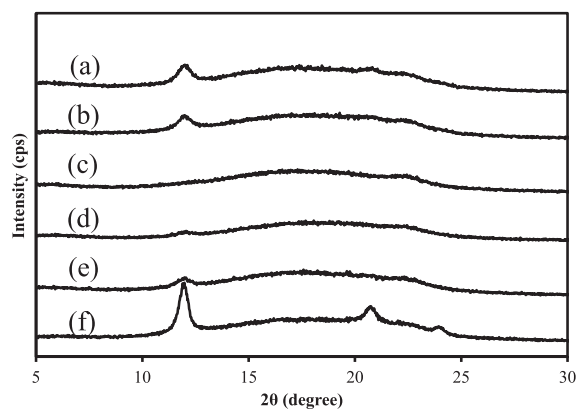

Fig. 11 WAXS patterns of the electrospun and annealed fibers obtained at different voltages from the dope of $10 \mathrm{wt} \%$ in polymer concentration: (a) as-isolated from solution (control), electrospun at (b) $5 \mathrm{kV}$, (c) $10 \mathrm{kV}$, (d) $15 \mathrm{kV}$, and (e) $20 \mathrm{kV}$, and (f) electrospun at $20 \mathrm{kV}$ and annealed at $140{ }^{\circ} \mathrm{C}$. 
Table 2 Results of Diels-Alder reaction of F-PDLA-F and M-PLLA-M.

\begin{tabular}{cccc}
\hline \multirow{2}{*}{ Sample } & $\mathrm{Mn}^{\mathrm{a}}$ & $\mathrm{Mw}^{\mathrm{a}}$ & $\mathrm{Mw} / \mathrm{Mn}^{\mathrm{a}}$ \\
\cline { 2 - 3 } & $\times 10^{3}$ & $\times 10^{3}$ & \\
\hline mix & 18.2 & 29.1 & 1.6 \\
$10 \mathrm{kV}$ & 24.7 & 44.1 & 1.8 \\
$15 \mathrm{kV}$ & 26.4 & 56.8 & 2.2 \\
$20 \mathrm{kV}$ & 23.5 & 45.6 & 1.9 \\
$20 \mathrm{kV}$ anneal & 42.6 & 127 & 2.9 \\
\hline
\end{tabular}

a) Determined by SEC relative to Ps standards with $\mathrm{CHCl}_{3}$ as the eluent.

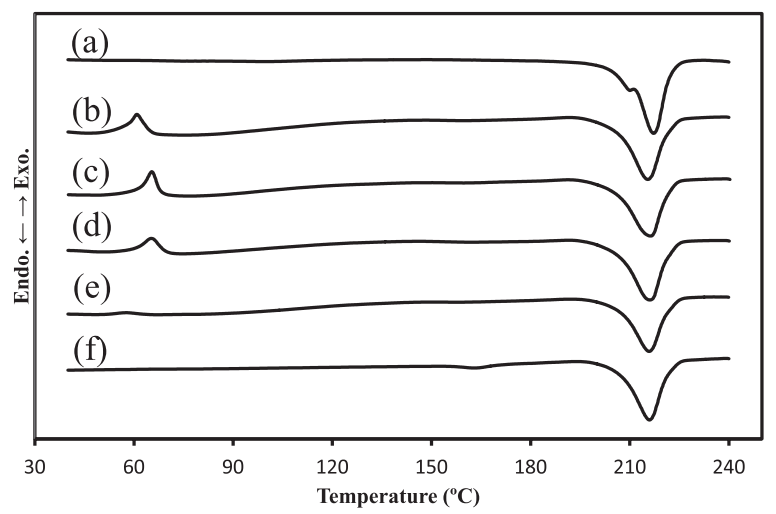

Fig. 12 DSC diagrams of the fibers electrospun at different voltages from the dope of $20 \mathrm{wt} \%$ in polymer concentration: (a) as-isolated from the prepolymer solution (control), electrospun at (b) $5 \mathrm{kV}$, (c) $10 \mathrm{kV}$, (d) $15 \mathrm{kV}$, and (e) $20 \mathrm{kV}$, and (f) electrospun at $20 \mathrm{kV}$ and annealed at $140{ }^{\circ} \mathrm{C}$.

slightly lower $\Delta \mathrm{H}_{\mathrm{m}}$ of the as-spun fibers was also noted here. After the annealing, the value approached that of the control in the second heating. The $\Delta \mathrm{H}_{\mathrm{m}}$ values recorded for the fusion of sc crystals are all significantly higher than those recorded by the Diels-Alder adducts between the anthracene-terminated PDLA and maleimideterminated PLLA reported before [21]. The higher values may be attributed to the stabilization of the sc crystals by the intermolecular hydrogen bonding between the amide groups present in the PDLA terminals.

\section{Conclusion}

The telechelic M-PLLA-M having di-maleimide (dienophile) terminals and F-PDLA-F having di-furan (diene) terminals were successfully synthesized by isocyanate coupling reactions of M-PLLA and F-PDLA that had been prepared by the ordinary ROP of L- and Dlactides with MA and FA as the initiators, respectively. By using a concentrated polymer solution of a 1 :
Table 3 Thermal properties of (a) the as-isolated product from the solution (control) and the fibers electrospun at (b) $20 \mathrm{kV}$ and (c) electrospun at $20 \mathrm{kV}$ and annealed at $140{ }^{\circ} \mathrm{C}$.

\begin{tabular}{ccccccccc}
\hline & \multicolumn{2}{c}{$1 \mathrm{st}$} & & \multicolumn{5}{c}{ 2nd } \\
\cline { 2 - 5 } \cline { 6 - 8 } Sample & $\mathrm{Tm}$ & $\Delta \mathrm{Hm}$ & & $\mathrm{Tg}$ & $\mathrm{Tc}$ & $\mathrm{Tm}$ & $\Delta \mathrm{Hm}$ \\
\cline { 2 - 5 } \cline { 6 - 8 } & ${ }^{\circ} \mathrm{C}$ & $\mathrm{J} / \mathrm{g}$ & & ${ }^{\circ} \mathrm{C}$ & ${ }^{\circ} \mathrm{C}$ & ${ }^{\circ} \mathrm{C}$ & $\mathrm{J} / \mathrm{g}$ \\
\hline (a) control & 217.3 & 80.9 & & 54.4 & 84.4 & 215.5 & 71.8 \\
(b) as-spun & 216.0 & 61.2 & & 54.3 & 83.8 & 215.0 & 59.9 \\
(c) annealed & 216.0 & 64.4 & & 55.7 & 85.1 & 215.6 & 68.9 \\
\hline
\end{tabular}

1 mixture of M-PLLA-M and F-PDLA-F in $\mathrm{CH}_{2} \mathrm{Cl}_{2}$, electrospinning was conducted to obtain thin fibers of $\mathrm{m}$-sb-PLA. In this process, the initial concentration of the polymers was allowed to increase up to $20 \mathrm{wt} \%$ with the fiber diameter being retained from submicron to nanometer order because of their low molecular weight. The molecular weight of the polymers was found to have increased from $1.0 \times 10^{4}$ to 2.5 and $4.5 \times 10^{4}$ after the electrospinning and post annealing, respectively, due to the spontaneous chain extension taking place by the terminal Diels-Alder reaction of M-PLLA-M and F-PDLA-F. The as-spun fibers were amorphous or semicrystalline but became fully crystalline by annealing. The fibers were found to consist exclusively of sc crystals without any he crystallization occurring. The present reactive electrospinning technique involving the DielsAlder coupling may be a good tool for manufacturing the sc-PLA-based materials.

\section{Acknowledgements}

This work was supported by the Kyoto Environmental Nanotechnology Cluster from the Ministry of Education, Culture, Sports, Science and Technology (MEXT). Musashino Chemical Laboratory, Ltd. and Mutual Co. Ltd. are highly acknowledged for their support and helpful discussions.

\section{References}

1. S. I. Moon, C. W. Lee, M. Miyamoto, and Y. Kimura, Polymer, 42, 5059 (2001).

2. A. P. Gupta, and V. Kumar, European Polymer Journal, 43, 4053 (2007).

3. Y. Kimura, Polymer Journal, 41, 797 (2009).

4. W. J. Groot, and T. Boren, Int J life Cycle Assess, 15, 970 (2010).

5. J. R. Dorgan, H. Lehermeier, and M. Mang, J. Polym. Environ., 8, 1 (2000). 
6. H. Tsuji, S. H. Hyon, and Y. Ikada, Macromolecules, 24, 5651 (1991).

7. H. Tsuji, S. H. Hyon, and Y. Ikada, Macromolecules, 25, 2940 (1992).

8. Y. Fan, H. Nishida, Y. Shirai, Y. Tokiwa, and T. Endo, Polym. Degrad. Stab., 86, 197 (2004).

9. Y. Furuhashi, Y. Kimura, N. Yoshie, and H. Yamane, Polymer, 45, 5972 (2006).

10. H. Yamane, Nihon Reoroji Gakkaishi, 27, 213 (1999).

11. J. Zhang, K. Tahiro, H. Tsuji, and A. J. Domb, Macromolecules, 40, 1049 (2007).

12. D. Masaki, Y. Fukui, K. Toyohara, M. Ikegame, B. Nagasaka, and H. Yamane, Sen'i Gakkaishi, 64, 212 (2008).

13. K. Fukushima, Y. Furuhashi, K. Sogo, S. Miura, and Y. Kimura, Macromol. Biosci., 5, 51 (2005).

14. K. Fukushima, and Y. Kimura, Macromol. Symp., 224, 133 (2005).

15. K. Fukushima, and Y. Kimura, J. Polym. Sci., Part A : Polym. Chem., 46, 3714 (2008).

16. K. Fukushima, and Y. Kimura, Polym. Int., 55, 626 (2006).

17. N. Yui, P. J. Dijkstra, and J. Feijen, Macromol. Chem., 191, 481 (1990).

18. H. Tsuji, T. Wada, Y. Sakamoto, and Y. Sugiura, Polymer, 51, 4937 (2010).

19. M. Hirata, K. Kobayashi, and Y. Kimura, J. Polym. Sci., Part A : Polym. Chem., 48, 794 (2010).
20. M. Kakuta, M. Hirata, Y. Kimura, J. Macromol. Sci., Part C: Polym. Rev., 49, 107 (2009).

21. K. Masutani, S. Kawabata, T. Aoki, and Y. Kimura, Polym. Int., 59, 1526 (2010).

22. K. Ishida and N. Yoshie, Macromol. Biosci., 8, 916 (2008).

23. K. Ishida, V. Weibel, and N. Yoshie, Polymer, 52, 2877 (2011).

24. K. Inoue, M. Yamashiro, and M. Iji, Journal of Applied Polymer Science, 112, 876 (2009).

25. K. Inoue, M. Yamashiro, and M. Iji, Koubunshi Ronbunshu, 62, 2261 (2005).

26. A. M. Afifi, M. Ymamoto, H. Yamane, Y. Kimura, A. E. Salmawy, and S. Nakano, Sen 'i Gakkaishi, 67, 21 (2011).

27. A. M. Afifi, H. Nakajima, H. Yamane, Y. Kimura, and S. Nakano, Macromol. Mater. Eng., 294, 265 (2009).

28. A. M. Afifi, H. Yamane, and Y. Kimura, Sen'i Gakkaishi, 66, 37 (2010).

29. K. H. Lee, H. Y. Kim, M. S. Khil, Y. M. Ra, and D. R. Lee, Polymer, 44, 1287 (2003).

30. X. Zong, S. Ran, D. Fang, B. S. Hsiao, and B. Chu, Polymer, 4, 4959 (2003).

31. J. Zhu, Y. Zhang, H. Shao, and X. Hu, Polymer, 49, 2880 (2008).

32. X. Zong, K. Kim, D. Fang, S. Ran, B. S. Hsiao, and B. Chu, Polymer, 43, 4403 (2002).

33. L. Li, L. M. Bellan, H. G. Craighead, and M. W. Frey, Polymer, 47, 6208- 6217 (2006). 